ISSN 2179-345X

\title{
Judicialização da política de proteção ambiental na expansão da exploração do petróleo no Espírito Santo
}

\author{
Judicialization of the environmental \\ protection policy in the expansion of oil \\ exploration in Espírito Santo
}

\section{Nelson Camatta Moreira ${ }^{[a]}$, Rodrigo Santos Neves ${ }^{[b]}$, Silvana Mara de Queiroz Bessa ${ }^{[c]}$, Alexsandro Broeto Rudio ${ }^{[d]}$}

[a] Doutor em Direito pela Universidade do Vale do Rio dos Sinos (UNISINOS), bolsa de estudos da Capes, na Universidade de Coimbra, professor da Faculdade de Direito e do Mestrado em Ciências Sociais da Universidade Vila Velha (UVV), Mestre em Direito da Faculdade de Direito de Vitória (FDV), Diretor da Escola Superior de Advocacia (ESA/OAB-ES), Vila Velha, ES - Brasil.

[b] Mestre em Direito pela Universidade Cândido Mendes (UCAM), professor da Universidade Vila Velha (UVV), Vila Velha, ES - Brasil.

[c] Aluna da Faculdade de Direito da Universidade Vila Velha (UVV), bolsista de Iniciação Científica, Vila Velha, ES - Brasil

[d] Aluno da Faculdade de Direito da Universidade Vila Velha (UVV), bolsista de Iniciação Científica, Vila Velha, ES - Brasil. 


\section{Resumo}

A investigação relativa à exploração do petróleo no estado do Espírito Santo e a interferência do Poder Judiciário é de extrema importância, tendo em vista que a referida atividade econômica atrai muitos recursos financeiros para esse ente federativo. No entanto, há que se considerar que a exploração de petróleo, embora extremamente lucrativa, apresenta grande risco ambiental. Daí a necessidade de prevenção e avaliação desses riscos. Como se sabe, antes da exploração de uma atividade econômica potencialmente danosa ao meio ambiente é necessária a elaboração de um estudo prévio de impacto ambiental, a fim de prevenir os danos ao meio ambiente. Após esse estudo, o administrador pode emitir licença ambiental para a exploração da atividade econômica, ou não. É nesse momento que o Poder Judiciário pode ser convocado a intervir em uma atividade típica da Administração Pública, com o intuito de tentar preservar um direito fundamental, que é o meio ambiente ecologicamente equilibrado. Todavia, essa interferência pode gerar diversas discussões envolvendo, inclusive, a própria legitimidade de atuação desse Poder. Assim, o presente texto aborda o tema "controle da Administração Pública pelo Poder Judiciário", tendo como base a investigação bibliográfica e jurisprudencial.

Palavras-chave: Meio ambiente. Poder Judiciário. Ativismo judicial.

\section{Abstract}

The investigation concerning oil exploration in the state of Espírito Santo as well as the interference of the Judiciary is extremely important, taking into account that this economic activity attracts many financial resources to this federal state. Nevertheless, it is important to consider that oil exploration, despite being very profitable, presents a high environmental risk. Thus, the necessity of prevention and evaluation of these risks arises. As it is known, before the exploration of any economic activity that is considered to be potentially harmful to the environment it is necessary to elaborate a previous study of environmental impact aiming at preventing damages to the environment. After this study the government may issue an environmental license for the exploration of that economic activity, or not. It is then that the Judiciary might be summoned to intervene in a typical government duty, with the attempt to try to preserve a fundamental right, that is, an ecologically balanced environment. However, this interference may generate various debates even involving the legitimacy of the Judiciary 
action. Then, this article discusses the issue "Public Administration control by the Judiciary", having as its basis a bibliographical and a judicial investigation as well

Keywords: The environment. The judiciary. Judicial activism.

\section{Introdução}

Diante do progressivo movimento de conscientização acerca da proteção do meio ambiente, no âmbito jurídico, a partir da Constituição de 1988, nota-se uma galopante preocupação com a questão do equilíbrio ecológico como uma condição, inclusive, para a afirmação da dignidade humana, prevista, por sua vez, como um dos fundamentos do Estado Democrático de Direito brasileiro. Em outras palavras, hodiernamente, não é possível imaginar uma sociedade preocupada com a questão da dignidade humana que não associe a sua afirmação à preocupação com o ecossistema, do qual o homem faz parte.

No entanto, a preservação do meio ambiente não é um fim em si mesmo. Ela está inserida em um contexto maior relacionado com a globalização, principalmente em sua vertente econômica que, por sua vez, no ordenamento jurídico pátrio, é objeto de preocupações de diferentes matizes, encontrando seu ponto de partida na própria "ordem econômica", sugerida pela Constituição de 1988 (BRASIL, 1988).

Assim, considerando-se a sistemática do texto constitucional que prevê princípios como a livre-iniciativa na economia, de um lado, regrado por uma ordem social, que inclui uma preocupação patente com a questão ambiental (art. 225, da CF/1988); de outro, é possível perceber que toda a complexidade da sociedade contemporânea, inexoravelmente, aporta no direito, que se torna um locus de convergência para a discussão de temas que tanto afligem a humanidade no século XXI.

Diante disso, o que se espera do intérprete da Constituição é uma postura hermenêutica capaz de enfrentar devidamente questões 
extremamente complexas e delicadas que espelham a ampla temática do desenvolvimento em suas diferentes perspectivas: econômica, social e de qualidade de vida em um mundo ecologicamente equilibrado.

Assim, dentre os vários enfoques possíveis ao estudo do Direito Constitucional Ambiental, o texto a seguir pretende analisar a maneira como tem se manifestado o judiciário brasileiro - especialmente a Corte Constitucional (STF) - acerca do papel do Estado e os limites de atuação (intervenção) do homem no meio ambiente. Dito de outra forma, o estudo ora apresentado intentou mapear a possível ingerência do Poder Judiciário, por meio de suas decisões, nas políticas públicas do Estado em relação ao meio ambiente.

Este é, portanto, o ponto de partida (e, talvez, de chegada) justificador da presente pesquisa, qual seja, a imperiosa necessidade de se (re)discutir as possibilidades interpretativas (hermenêuticas) abertas pela Constituição de 1988 para o judiciário brasileiro, no Estado Democrático de Direito, em relação à sua contribuição para um ambiente ecologicamente equilibrado "para as presentes e futuras gerações" (art. 225, da CF/1988), bem como o freio a ele imposto pela consagrada limitação de ingerência nos demais poderes (art. $2^{\circ}$, da CF/1988).

\section{O judiciário, a lei e o meio ambiente na era da globalização: breves comentários}

Inegavelmente, o fenômeno da globalização e do advento da denominada "sociedade do risco" marcam um período complexo de transição histórica, operando profundas modificações nas mais variadas dimensões da realidade. Isso torna possível perceber seus impactos na base do paradigma jurídico-político da modernidade e seus reflexos no paradigma do Direito moderno.

Tal paradigma, no seio das transições societal e epistemológica protagonizadas pelo surgimento da pós-modernidade, tem sofrido profundos abalos, questionamentos, desestruturação e desmontes. 
A sinalização de sua crise emblemática impõe, em contrapartida, a elaboração de tentativas de sua superação, cujos fundamentos conduzem às suas novas caracterizações e roupagens.

Assim, impõe-se discutir os limites do direito moderno para tutelar satisfatoriamente os novos bens jurídicos de natureza supraindividual, em especial o meio ambiente. De outro lado, essa nova forma de sociedade globalizada, ao permitir um amplo intercâmbio de informações, mercadorias, símbolos, signos, ideologias e métodos de poder e de domínio, cada vez mais acelerada em escala global, acaba por ampliar a produção de um constante perigo. Os novos riscos, produto inexorável da crescente expansão tecnológica e informacional deste século, suscitam, no Direito, problemas novos e de difícil enquadramento em seus métodos, premissas, hipóteses e categorias convencionais.

No Direito, não obstante todas as crises que envolvem a sua aplicação em um tempo instantaneísta (BAUMAN, 2001) de uma sociedade extremamente complexa, conflitiva e globalizada (BECK, 1998; GUIDDENS, 1991; DI GIORGI, 1998), as questões que chegam à apreciação do Poder Judiciário ainda são lidas sob a lente da lei, cuja maior expressão é a Constituição. E a decisão ainda se constitui como o principal mecanismo de manutenção ou transformação da realidade social. Assim, como mais um fenômeno que compõe essa complexa realidade, a questão ambiental, em seus diversos matizes, aparece como um nobre objeto sobre o qual se discute e se repercutem as decisões do Estado.

Nessa perspectiva, o texto mostra privilegiadamente as manifestações (decisões) do Poder Judiciário sobre o meio ambiente, a partir da análise de decisões sobre o licenciamento de petróleo no Espírito Santo que tenham sido ou que estejam prestes a ser apreciadas - talvez revistas - pelo Poder Judiciário.

Dito de outra forma, o texto discute as possibilidades hermenêuticas de intervenção desse poder em questões eminentemente de política de proteção ambiental e de política de desenvolvimento econômico social, podendo esbarrar em uma temática muito polêmica em dias 
atuais: $o$ ativismo judicial ${ }^{1}$, que, para Garapon ${ }^{2}$, consiste em um processo "natural" desenvolvido no interior de um Estado Democrático, até porque a interferência judiciária é um fenômeno possibilitado, na prática, pelos próprios políticos.

A respeito das possibilidades hermenêuticas, analisam-se os argumentos das decisões, buscando-se compreender a maneira como são elaborados, se se coadunam com o discurso principiológico da Constituição e, mais, se atendem aos anseios de uma sociedade que pretende ser livre, justa e fraterna (Preâmbulo da Constituição de 1988). Para tanto, tentar-se-á empreender aqui uma "compreensão da compreensão" do Poder Judiciário sobre o licenciamento para a exploração do petróleo no Espírito Santo e, se necessário, como parâmetro, em outros Estados da federação que se enquadram em realidade similar à capixaba.

É importante mencionar ainda que, no âmbito normativo, para o enfrentamento específico do direito ou não à licença ambiental para a exploração de petróleo - que é o exemplo privilegiado de intervenção estatal na proteção do meio ambiente e ao mesmo tempo na intervenção do domínio econômico - não se pode olvidar a importância da legislação

1 Essa terminologia, que remete à discussão sobre a interferência judicial no mundo político, mantémse em voga no debate público e acadêmico. Por isso, é importante deixar registrado, desde esse primeiro momento em que tal expressão aparece aqui no texto, que o ativismo judicial pode ser compreendido a partir de várias perspectivas: algumas positivas, que mostram a necessidade de um juiz comprometido com os valores culturais e com os princípios jurídicos (a interpretação do juiz deve ser constrangida pelo princípio da coerência normativa face à história do seu direito e da sua cultura jurídica, como mostra DWORKIN, R. O império do Direito. Tradução de Jéferson L. Camargo. São Paulo: M. Fontes, 2003; outras negativas, como a de Habermas, por exemplo, que entende que assim como o legislador não tem competência para julgar se os tribunais aplicam correta e justamente o direito, também não têm os juízes o direito de intervir na substância do processo legislativo, controlando abstratamente as suas normas (HABERMAS, J. Direito e democracia: entre facticidade e validade. 2. ed. Rio de Janeiro: Tempo Brasileiro, 2003).

2 "A sociedade democrática desfaz os laços sociais e os refaz socialmente. Ela é obrigada, hoje, a fabricar o que antigamente era outorgado pela tradição, pela religião ou pelos costumes. Forçada a 'inventar' a autoridade, sem sucesso, ela acorre então para o Juiz" (GARA GARAPON, A. O juiz e a democracia: o guardião de promessas. Tradução de Maria L. de Carvalho. Rio de Janeiro: Renovar, 1999. p. 140).

Revista de Direito Econômico e Socioambiental, Curitiba, v. 3, n. 1, p. 79-105, jan./jun. 2012 
infraconstitucional sobre o assunto, com especial destaque para a Lei n. 9478/97. Tal lei, inclusive, criou a Agência Nacional do Petróleo, Gás Natural e Biocombustíveis (ANP), cujas atribuições são, dentre outras, fazer cumprir as boas práticas de conservação e uso racional do petróleo, gás natural, seus derivados e biocombustíveis e de preservação do meio ambiente (art. $8^{\circ}$, IX, Lei n. 9478/97).

Em síntese, o objetivo dessa lei é estabelecer as políticas nacionais de aproveitamento racional de energia no sentido de proteger o meio ambiente e promover a conservação de energia (art. $1^{\circ}$, IV, Lei n. $9478 / 97)^{3}$.

\section{A expansão econômica, os valores sociais e o meio ambiente}

Embora exista uma preocupação governamental quanto ao crescimento do PIB do país, essa não pode ser a única preocupação do governo nem dos atores econômicos. Em outras palavras, a propriedade privada, que é um valor constitucional a ser observado e protegido pelo ordenamento jurídico, tendo em vista o seu caráter de direito fundamental (art. $5^{\circ}$, XXII, CR/88), bem como de princípio da Ordem Econômica, deve ser compatibilizada com outros valores constitucionalmente consagrados, dentre eles a função social da propriedade e a dignidade da pessoa humana ${ }^{4}$.

Assim, as atividades econômicas, como expressão da propriedade privada, devem se preocupar com a promoção da dignidade da pessoa humana. A tutela do meio ambiente, com a preocupação na

3 Sobre o assunto conferir: MACHADO, P. A. L. Direito Ambiental brasileiro. 17. ed. São Paulo: Malheiros: 2009. p. 294-296; MILARÉ, É. Direito do ambiente: a gestão ambiental em foco. 6. ed. São Paulo: RT, 2009. p. 418-482; FONTENELLE, M; AMENDOLA, C. M. Licenciamento ambiental do petróleo e gás natural. Rio de Janeiro: Lumen Juris, 2003; SILVA, J. A. da. Direito Ambiental Constitucional. 7. ed. São Paulo: Malheiros, 2009.

4 A esse respeito v. NEVES, R. S. O Estado regulador: a dignidade humana como princípio informador da regulação do mercado. Revista de Direito Constitucional e Internacional, São Paulo, v. 44, p. 209233, 2003. 
garantia de seu equilíbrio, tem por finalidade última garantir a vida digna, não se olvidando, contudo, a proteção da propriedade privada e da livre-iniciativa.

No entanto, o que se precisa saber é até que ponto a livre-iniciativa deve ser "liberada" para a promoção do desenvolvimento econômico, afetando o equilíbrio ecológico de determinada região. Assim, o grande problema que se tem no ordenamento jurídico brasileiro é o equilíbrio desses dois valores constitucionais. O grande desafio consiste então em se saber como promover o desenvolvimento econômico sem prejudicar o meio ambiente. E mais: como ainda contribuir devidamente para o avanço social como determinado pela Constituição?

Do ponto de partida traçado na introdução do presente texto, portanto, tem-se agora a justificativa do seu desenvolvimento: a renovada necessidade de se discutir as angústias problematizadas anteriormente com enfoque na atuação do Poder Judiciário sobre o desenvolvimento econômico e social, com cuidadosa atenção na questão ambiental, mais especificamente no impacto gerado pela exploração do petróleo.

\section{O judiciário e a proteção do meio ambiente}

Nos moldes do art. 225, da CF/88, o cuidado com o meio ambiente passou a ser considerado um direito-dever para todos. $\mathrm{O}$ texto constitucional ainda elevou a defesa do meio ambiente à condição de princípio norteador da ordem econômica (art. 170, VI, CR/88). Destarte, toda e qualquer atividade econômica, bem como os serviços públicos, deverá sempre levar em consideração a questão ambiental, sob pena de ofensa à lei fundamental.

Não obstante a atuação preponderante do Poder Executivo na fiscalização das atividades econômicas, as partes em conflito (Poder Público e particulares ou somente particulares) podem recorrer ao Judiciário para a solução dos conflitos, o que exige do julgador a sensibilidade dos problemas existentes, bem como exige uma atividade hermenêutica eficiente, 
capaz de sopesar os interesses em jogo, para dar uma solução adequada ao caso concreto.

A consagração constitucional (art. 225, $\S 1^{\circ}$, incisos I ao VII, da $\mathrm{CF} / 88$ ) do dever de preservação do meio ambiente impôs ao Estado uma série de medidas para a efetiva proteção do meio ambiente equilibrado.

Assim, em face de eventual omissão da Administração Pública na realização dessas atividades protetivas e restauradoras, os interessados (legitimados) podem provocar o Poder Judiciário para que a Administração Pública e/ou o particular sejam compelidos a cumprir os seus deveres. É a chamada judicialização da política, que pode ser entendida como:

a invasão do direito sobre o social avança na regulação dos setores mais vulneráveis, em um claro processo de substituição do Estado e dos recursos institucionais classicamente republicanos pelo judiciário, visando a dar cobertura à criança e ao adolescente, ao idoso e aos portadores de deficiência física. $\mathrm{O}$ juiz torna-se protagonista direto da questão social. Sem política, sem partidos ou uma vida social organizada, o cidadão volta-se para ele, mobilizando o arsenal de recursos criado pelo legislador a fim de lhe proporcionar vias alternativas para a defesa e eventuais conquistas de direitos. A nova arquitetura institucional adquire seu contorno mais forte com o exercício do controle da constitucionalidade das leis e do processo eleitoral por parte do judiciário, submetendo o poder soberano às leis que ele mesmo outorgou (VIANNA; BURGOS; SALLES, 2007, p. 41).

Assim, o Poder Judiciário ganhou papel fundamental na democracia brasileira, na medida em que a sociedade pode exercer o controle social sobre a atuação da Administração Pública via Poder Judiciário, em ações populares, ou por meio do Ministério Público, em ações civis públicas, com o fim de tutelar o meio ambiente sempre que este estiver em perigo.

Dessa forma, a atuação dos juízes e tribunais deve tomar uma feição proativa e protetiva, de modo a romper com o paradigma liberal. Nesse paradigma, o juiz tem um (pseudo) papel de "neutralidade", em observância à discricionariedade administrativa, passando a atuar como 
agente político que é, de modo a fazer valer os valores e princípios constitucionalmente protegidos (SARLET; FENSTERSEIFER, 2008, p. 81-82). A questão ambiental, como está diretamente vinculada ao texto constitucional, traz à discussão muitos valores constitucionais e que, ao menos em princípio, são antagônicos, tais como a dignidade da pessoa humana, o direito ao meio ambiente equilibrado, a propriedade privada, a função social da propriedade e a livre-iniciativa. Por isso, o juiz deverá levar em consideração todos esses valores, tendo em vista que na questão ambiental é muito provável que haja colisão de direitos fundamentais. Assim, o intérprete deverá fazer uso da hermenêutica constitucional, a fim de que possa apresentar, em suas decisões, resultados satisfatórios.

Em matéria ambiental, os tribunais têm aplicado os efeitos horizontais dos direitos fundamentais - no caso, o direito fundamental ao meio ambiente equilibrado. Seja com a limitação aos direitos do proprietário rural para respeitar uma unidade de conservação, ou uma área de preservação permanente, ou respeitar a reserva legal, mesmo que o novo proprietário já tenha comprado o imóvel com reserva legal desmatada, em que lhe é imputado o dever de reflorestar.

O STJ decidiu que um proprietário demolisse uma construção feita dentro de uma Área de Preservação Permanente. A construção era de um complexo hoteleiro ${ }^{5}$. O mesmo tribunal, em Ação Civil Pública que tinha por objeto a anulação de licença ambiental para explorar árvores mortas ou caídas de determinada área particular e que, posteriormente, se tornara um Parque Nacional, por decreto de utilidade pública, decidiu que não apenas em função da criação do Parque e da consequente transferência de propriedade para o domínio público, mas sim em função do laudo técnico afirmava que:

as operações de extração de madeira, com a presença de barulho de máquinas, equipe de trabalhadores e arrasto de toras, possivelmente farão com que determinadas espécies, principalmente da fauna terrestre, se afastem desta agitação procurando outras áreas, podendo assim

5 STJ, 1‥ T., Rel. Min. Luiz Fux, MC n. 16868 - SP, DJ 05.10.10. 
invadir áreas antropizadas ficando mais suscetíveis à caça e predação. Além do que, como citado no trabalho do engenheiro Eloi Mattei, a fauna poderia retornar à área após a operação de retirada. Porém, vale salientar que se alguma destas espécies estiver se reproduzindo no local, este deslocamento da área e posterior retorno não seria assim tão simples e talvez inviável acarretando provavelmente na perda da prole, o que seria extremamente agravante se tratando de espécie com grande longevidade e baixo índice de natalidade ${ }^{6}$.

Em outro caso, o STJ, ainda, no REsp n. 1.079.713-SC condenou uma empresa ao pagamento de indenização por danos ao meio ambiente, por queimar palha de cana, mesmo com licença ambiental para tanto, por entender que, além da existência de danos ao meio ambiente, a licença foi concedida indevidamente.

Como se vê, em diversos julgados os tribunais têm se manifestado a respeito da questão ambiental, não obstante as concessões de licenças para explorar o desenvolvimento de atividades econômicas de forte repercussão (impacto) ambiental.

\section{Por que o petróleo? A atualidade da pesquisa e as possíveis contribuições para o delineamento da atuação do Poder Judiciário nessa temática no Estado do Espírito Santo}

Como já é de pleno conhecimento público, no Estado do Espírito Santo, reconhecidamente rico em petróleo, os avanços na pesquisa e na exploração desse recurso natural vêm sendo brutais, conforme noticia o site oficial do governo estadual:

6 STJ, REsp n. 1.122.909-SC, 2a . T, Rel. Min. Humberto Martins, DJ 07.12.09. Recurso Especial n. 1.079.713 -SC (2008/0169678-0). Disponível em: <http://www.jusbrasil.com.br/jurisprudencia/6061190/recursoespecial-resp-1079713-sc-2008-0169678-0-stj/inteiro-teor>. Acesso em: 27 dez. 2011. 
nos últimos anos, o Espírito Santo foi destaque na produção de petróleo e gás natural no Brasil. Com as descobertas realizadas, principalmente pela Petrobras, o Estado saiu da $5^{\text {a }}$ posição no ranking brasileiro de reservas, em 2002, para se tornar a segunda maior província petrolífera do País, com reservas totais de 2,5 bilhões de barris.

Atualmente, o Estado é o segundo maior produtor de petróleo do Brasil, com 140 mil barris diários. Até o final deste ano, este número deve chegar a 200 mil barris por dia, e em 2010, atingirá a marca de 500 mil barris/dia. Os campos petrolíferos se localizam tanto em terra quanto em mar, em águas rasas, profundas e ultra-profundas, contendo óleo leve e pesado e gás não associado.

[...]

O Espírito Santo é hoje responsável por $40 \%$ das notificações de petróleo e gás natural, conforme levantamento da Agência Nacional do Petróleo, Gás Natural e Biocombustível (ANP) desde sua criação, em janeiro de 1998 (GOVERNO DO ESTADO DO ESPÍRITO SANTO, 2009).

A promessa de crescimento na área, a cada dia, transforma-se em realidade. Os diferentes impactos são notados na sociedade e no Estado. Segundo a mídia nacional,

a expectativa em torno da possibilidade de descobertas de novas áreas para a exploração de petróleo no litoral do Espírito Santo desencadeou uma fase de otimismo entre os empresários da região. De cursos universitários a empreendimentos imobiliários, Vitória e cidades vizinhas já movimentam cifras com a promessa de descoberta de novas reservas de gás e óleo (CARVALHO, 2004).

O processo evolutivo de investimento e movimentação do mercado do petróleo foi ainda mais estimulado com a decisão da Petrobras de construir uma sede administrativa regional em Vitória, ES, conforme anunciado oficialmente pela prefeitura da capital capixaba em 25 de abril de 2007, em um investimento de $\mathrm{R} \$ 426$ milhões (SALLES, 2007). Essa empresa é símbolo da exploração/gestão dessa riqueza no Brasil e, 
inclusive, até o advento da EC 9/957, detinha o monopólio de todas as atividades que envolviam desde a pesquisa até a comercialização do produto.

Tudo isso demonstra a importância deste assunto para o desenvolvimento do Estado e da sociedade capixaba. E, a reboque disso, a tendência natural, em qualquer tipo de sociedade que vivencia tamanha transformação, é aparecer os impactos negativos, os problemas, enfim, os conflitos que acabam "desaguando" no Poder Judiciário.

A expansão incessante da atuação do Judiciário em questões relevantes que envolvem o desenvolvimento socioeconômico na chamada judicialização da política, por meio do ativismo judicial, tende a assumir importantes contornos também na área ambiental, especificamente nesse importante tema que é o licenciamento do petróleo.

Nesse sentido, nota-se a importância da análise dos problemas jurídico-ambientais proporcionados pelo boom do mercado petrolífero no Estado do Espírito Santo, ou seja, o que (e como) se tem discutido sobre o impacto ambiental em todos os níveis do Poder Judiciário (Justiça Estadual e Federal, em diferentes instâncias).

\section{Um breve esclarecimento acerca das expressões: judicialização da política e ativismo judicial}

Diante de um Estado Social e Democrático de Direito, a palavra de ordem é efetividade. Nunca se falou tanto em efetividade das normas constitucionais como a partir de 1988, com a promulgação da Constituição da República de 1988 (CR/88). A busca por essa efetividade das normas constitucionais tem movimentado doutrina e jurisprudência, a fim de dar uma maior legitimidade ao ordenamento jurídico.

Ora, se a Constituição é a convergência das forças políticas existente no país, no exercício da democracia, a força normativa da constitui-

\footnotetext{
7 A Lei n. 9.478, de 1997, veio posteriormente regulamentar a atuação das empresas privadas na exploração do petróleo.
} 
ção impõe a interpretação que dê a maior efetividade possível das normas constitucionais, para que se garanta maior legitimidade ao ordenamento jurídico (BONIFÁCIO, 2009, p. 218). Essa busca pela efetividade das normas constitucionais tem por finalidade garantir a conformação jurídica de justiça (BONIFÁCIO, 2009, p. 222).

A judicialização da política é a deliberação de questões dessa ordem por órgãos do Poder Judiciário, sem qualquer tendência política. Quando o Judiciário é provocado pelos jurisdicionados, não há opção do Estado-juiz em decidir ou não. Se o conteúdo da demanda, ou seja, se o pedido e a causa de pedir são relacionados a um direito fundamental, por exemplo, que não tem sido garantido pelo Estado, cabe ao Judiciário se manifestar, a fim de garantir que o jurisdicionado tenha o seu direito reconhecido e cumprido por quem é obrigado.

"O direito assume um caráter marcadamente hermenêutico", explica Streck (2009), em função "de um efetivo crescimento no grau de deslocamento do pólo de tensão entre os poderes de Estado em direção à jurisdição (constitucional), diante da impossibilidade de o legislativo (a lei) poder antever todas as hipóteses de aplicação e do caráter compromissório da Constituição, com múltiplas possibilidades de acesso à justiça" (STRECK, 2009, p. 65).

O crescimento desse fenômeno tem três causas, em especial, que passamos a enumerar:

a) o processo de redemocratização do país, que a partir de 1988 tomou corpo, por meio: i) das garantias institucionais da magistratura - o que possibilita que o Judiciário não seja visto mais como um órgão técnico-jurídico do Estado, a fim de lhe dar suporte e garantir a independência dos juízes; ii) a ampliação das atribuições do Ministério Público, estabelecidas na $\mathrm{CR} / 88$, que, por meio da ação civil pública, tem legitimidade para requerer a tutela de interesses difusos e coletivos; iii) assim como o crescimento da presença das defensorias públicas, no âmbito estadual 
e federal, o que possibilita o acesso da população menos prestigiada ao Poder Judiciário para a proteção dos seus interesses;

b) a abrangência temática da constituição, que fica demonstrada em sua forma analítica, com a constitucionalização de diversos temas, tais como tributação, educação, saúde, desporto, assistência social, trabalho, além do extenso rol de direitos fundamentais, sem falar na cláusula geral de abertura inserida no art. $5^{\circ}$, $\S 2^{\circ}, \mathrm{CR} / 88$; além disso,

c) o sistema brasileiro de controle de constitucionalidade, que comporta o controle difuso, em que qualquer juiz pode declarar uma lei ou ato normativo como inconstitucional, mesmo de ofício, ou por meio do controle concentrado, via ação direta, exercido pelo STF, por meio da ação direta de inconstitucionalidade, da ação declaratória de constitucionalidade, ação de inconstitucionalidade por omissão e pela arguição de descumprimento de preceito fundamental.

No entanto, diante da necessidade de efetivação dos direitos fundamentais, em especial no que se refere aos direitos fundamentais sociais, a atividade do juiz pode fazer as vezes de atividade política, típica dos Poderes Legislativo e Executivo, o que pode representar uma violação do princípio da separação de poderes (art. $\left.2^{\circ}, \mathrm{CR} / 88\right)^{8}$.

O ativismo judicial é, portanto, a atividade pela qual o Poder Judiciário, no exercício de suas funções, atua de modo proativo, a fim de interpretar a Constituição de modo a garantir a efetivação de direitos, diante de uma retração na atuação dos outros Poderes. É exatamente a possibilidade de confusão entre a atividade administrativa ou a formulação de políticas públicas e a atividade jurisdicional que coloca o ativismo judicial em uma situação delicada, diante da separação de poderes.

8 " $[\ldots]$ como se tem conhecimento da flagrante limitação dos recursos públicos para o atendimento da demanda social inesgotável, cabe ao magistrado fazer a ponderação de interesses e o exame de elementos de necessidade e adequação por ocasião do ato decisório concretizador desses direitos fundamentais" (RODRIGUES, 2009, p. 386). 


\section{A pesquisa jurisprudencial: a incipiente intromissão do judiciário no âmbito administrativo}

Na pesquisa realizada, com consideráveis contribuições dos alunos bolsistas de iniciação científica, na tentativa da coleta de dados presencialmente (nos fóruns de Vitória e Vila Velha e no Tribunal de Justiça Estadual, bem como na Justiça Federal sediada em Vitória) e virtualmente (nos sites do TJES e do TRF2), em diversas esferas do Judiciário, competentes para apreciar causas que envolvam o meio ambiente no Estado do Espírito Santo, percebeu-se a escassez de apreciações de questões envolvendo a exploração do petróleo pela "Justiça capixaba".

Essa escassez só não foi total em razão da existência da interessante decisão proferida pelo Juiz da $6^{\text {a }}$ Vara Federal Cível, na Seção Judiciária do Espírito Santo, nos autos do processo n. 2005.50.01.00.7655-9.

Trata-se de uma ação ordinária, movida pela Petrobras em face do Ibama, na qual aquela pleiteava a concessão imediata da licença prévia de produção para pesquisa no litoral do Espírito Santo. Isso havia sido negado por se entender que a requerente (Petrobras) não havia cumprido todas as suas exigências - que no caso era a realização de uma compensação ambiental, prevista no art. 36, caput, da Lei n. 9.985/2000.

De fato, o Ibama entendeu que o empreendimento produziria significativo impacto ao meio ambiente e, portanto, seria necessária a compensação ambiental, com a criação de uma unidade de conservação, ficando a sua criação e manutenção a cargo da Petrobras. Como a referida empresa não concordou com a exigência, por entender que sua atividade não provocaria significativo impacto ambiental, ela ajuizou a ação ordinária, para que o Poder Judiciário determinasse a concessão da referida licença ambiental.

Nesse sentido, parece tratar-se de um caso concreto de judicialização da política, uma vez que o Poder Judiciário poderia interferir na esfera administrativa e, talvez, tomar o lugar do administrador.

O juiz federal, ao analisar o caso, entendeu que todos os requisitos legais para a concessão da licença haviam sido preenchidos. Portanto, 
a negativa da concessão da licença seria ilegal, tendo em vista que a Petrobras apresentou os documentos listados no art. $7^{\circ}$ da Resolução Conama n. 23/97, dentre eles o estudo de viabilidade ambiental (EVA).

Desse modo, entendeu o magistrado que, como a referida resolução não trata da compensação ambiental, ela não é aplicável ao caso concreto. Se o Ibama quisesse exigir a compensação ambiental (art. 36, Lei n. 9.985/2000), deveria ter exigido o estudo prévio de impacto ambiental, conforme previsão nesse dispositivo legal.

Embora o Ibama tenha explicitado que o nome do documento deve ser tratado de modo genérico pelo intérprete, a tese que prevaleceu foi a da Petrobras, determinando o juiz a imediata concessão da licença ambiental para a pesquisa pretendida.

\section{Revisão de atos administrativos pelo Poder Judiciário ou judicialização da política na atividade petrolífera?}

Conforme prevê a Constituição, quando se trata de questão ambiental a Administração não deve agir apenas considerando um "direito subjetivo de exploração" de qualquer atividade econômica - livre-iniciativa -, mas sim a tutela do meio ambiente, em uma racionalidade que deve transcender a "lógica individualista burguesa" (BRASIL, 1988).

De acordo com o princípio da prevenção e o da precaução ${ }^{10}$, a Administração Pública tem por fim assegurar que os bens ambientais se-

9 O princípio da prevenção consiste na tomada de medidas preventivas de danos ao meio ambiente. Em vez de a Administração Pública punir os infratores da legislação ambiental, ela determina a realização de estudo de impacto ambiental, dentre outras medidas, para que se evitem danos ao meio ambiente (BELTRÃO, A. F. G. Curso de Direito Ambiental. São Paulo: Método, 2009. p. 35-36; MACHADO, 2009, p. 90-92).

10 O princípio da precaução se justifica pelas incertezas que rodeiam as questões ambientais. 0 princípio da prevenção avalia os riscos a partir da probabilidade de danos ao meio ambiente. 0 princípio da precaução, ao contrário, leva em consideração até mesmo os danos que são imprevisíveis, diante da falta de conhecimento do assunto e por se tratar da vida, a qual não é possível confinar nos laboratórios. Interessante é a afirmação de François Ost a respeito do tema: "quanto mais se sabe 
jam preservados de atividades econômicas danosas, mesmo que isso signifique a obstaculação de atividades econômicas, caso não seja possível a minimização dos danos ambientais em níveis aceitáveis.

A licença administrativa deve ser entendida como o instrumento pelo qual a Administração Pública autoriza que um administrado pratique determinados atos, no exercício de direitos subjetivos. Assim é a licença para dirigir veículo automotor, ou para construir, por exemplo.

Uma vez preenchidos os requisitos legais, não pode a Administração Pública se recusar a fornecer ao particular a referida licença, sob pena de praticar ato abusivo, atacável por mandado de segurança. Isso porque não há para o administrador nenhuma liberdade de escolha. Uma vez preenchidos os requisitos legais, o administrado tem o direito à expedição da licença (CARVALHO FILHO, 2010, p. 155). Além disso, os atos vinculados são definitivos. Uma vez praticados, não podem ser desfeitos por atos posteriores, salvo quando a própria lei estabeleça um prazo de validade para determinado ato (CARVALHO FILHO, 2010, p. 156).

Assim, no âmbito da dogmática jurídica, parte da doutrina (BELTRÃO, 2009, p. 132) entende que a licença ambiental tem natureza jurídica de licença e, portanto, vinculada, pelas seguintes razões:

a) se a licença ambiental for considerada uma autorização, não haveria direito subjetivo à exploração de atividades econômicas, o que colocaria o administrado à mercê da discricionariedade da Administração Pública; esse entendimento violaria nosso sistema constitucional, que garante a livre-iniciativa (art. 170, caput, $\mathrm{CR} / 88)$;

b) a possibilidade da não renovação, modificação, suspensão ou cancelamento da licença não significa a precariedade do ato

menos se afirma. Assim, será necessário conformar-se com um saber iminentemente revisável: o grande número de variantes introduzidas, bem como a multiplicidade dos elos recursivos operando entre si, frustram qualquer previsão intangível. É a uma actualização constante dos dados e a uma revisão periódica dos modelos explicativos que obriga o saber ecológico actual" (OST, F. A natureza à margem da lei: a ecologia à prova do Direito. Tradução de Joana Chaves. Lisboa: Piaget, 1995. p. 110).

Revista de Direito Econômico e Socioambiental, Curitiba, v. 3, n. 1, p. 79-105, jan./jun. 2012 
administrativo, porque não o coloca à mercê da arbitrariedade, tendo em vista que a não renovação não pode ocorrer de modo discricionário, mas sim de acordo com a lei (BELTRÃO, 2009, p. 132-133).

Aloísio Pereira Neto também defende a vinculação da licença ambiental. No entanto, se houver qualquer violação das condicionantes ou normas legais, a licença poderá ser cassada (PEREIRA, 2009, p. 260).

Por outro lado, a autorização "é o ato pelo qual a Administração consente que o particular exerça atividade ou utilize bem público no seu próprio interesse" (CARVALHO FILHO, 2010, p. 160). A autorização é um ato discricionário da Administração e precário. Portanto, a autorização pode ser cancelada a qualquer tempo.

É sabido que o art. $170, \S 1^{\circ}, \mathrm{CR} / 88$ assegura "a todos o livre exercício de qualquer atividade econômica, independentemente de autorização de órgãos públicos, salvo nos casos previstos em lei” (grifo nosso).

Como a proteção ambiental está inserida no contexto da Ordem Econômica, torna-se claro que as atividades econômicas, quando estão submetidas ao licenciamento ambiental, necessitam de uma autorização ambiental (MACHADO, 2009. p. 275). Além disso, outras razões podem ser explicitadas, como se vê a seguir.

O art. $10, \S 1^{\circ}$, da Lei n. 6.938/81 trata do pedido de renovação da licença, como forma de manifestar que essa licença ambiental tem natureza de autorização, diante da necessidade de renovação. Se fosse licença mesmo, esta se tornaria ato definitivo. A mesma lei, ao tratar dos instrumentos da Política Nacional do Meio Ambiente, aborda o licenciamento e a revisão das licenças, que, no mesmo sentido, demonstra a necessidade de revisão das licenças emitidas, com um caráter temporário.

A Resolução Conama n. 237/97 estabelece prazo de validade das licenças ambientais, em seu art. 18 - licença prévia não superior a cinco anos; licença de instalação não superior a seis anos; e licença de operação não superior a dez anos. A obrigatoriedade das licenças serem temporárias também demonstra que a licença ambiental tem natureza de autorização. 
Contudo, o que isso significa? As autorizações são atos administrativos precários. Não estão vinculados a direitos subjetivos dos administrados, podendo ser, a qualquer tempo, canceladas, por serem atos administrativos discricionários. Nos atos vinculados, a Administração não pode se negar a praticar o ato, uma vez preenchidos os requisitos legais. No entanto, o regime jurídico dos atos administrativos vinculados não é o adequado no que se refere à licença ambiental. Traduzindo-se para a linguagem filosófica de François Ost, percebe-se que:

a alternativa não poderia consistir senão num direito brando, puramente simbólico, desprovido de todo o efeito constrangente; ou então num direito excessivamente rígido e estável, sempre ultrapassado pelas realidades. Bem entendido, há um preço a pagar: os princípios de respeito à legalidade e da segurança jurídica não poderão sair indemnes deste embrandecimento da norma, em que a iniciativa é frequentemente delegada do legislador à administração, e cujo conteúdo é objecto de uma revisão contínua (OST, 1995, p. 115).

Diante de tantas condicionantes e levando-se em consideração que a tutela do meio ambiente se refere a um direito difuso, de interesse de toda a sociedade, não há como se permitir que a licença ambiental permaneça presa ao regime jurídico dos atos administrativos vinculados, por ser temerário dar muitos direitos subjetivos aos indivíduos, em detrimento do restante da sociedade.

Assim, para garantir uma maior efetividade à tutela ambiental, e diante do que já foi colocado pela legislação, há que se entender que a "licença ambiental”, na verdade, tem natureza jurídica de uma autorização e, portanto, é um ato administrativo discricionário.

Isso não quer dizer que os administrados estarão sujeitos à arbitrariedade do administrador, uma vez que é possível, como se sabe, controlar a discricionariedade da Administração.

$\mathrm{Na}$ decisão que se comenta neste trabalho, o julgado tratou a licença ambiental como ato vinculado. Assim, uma vez demonstrado o 
cumprimento das exigências legais e regulamentares, nasce um direito subjetivo para o administrado na expedição da licença ambiental.

No entanto, se a Administração negou a licença ambiental talvez seja porque havia elementos que colocavam em dúvida se a atividade da empresa causaria ou não danos ao meio ambiente. Nesse caso, quando o Estado-juiz profere decisão anulando aquela decisão de não conceder licença, ele interfere em um ato administrativo praticado pelo órgão administrativo competente (Ibama), tomando, assim, o lugar do administrador (?).

\section{Apontamentos conclusivos}

$\mathrm{Na}$ pesquisa desenvolvida no transcurso do ano de 2010, intitulada "Expansão da exploração do petróleo, política de proteção do meio ambiente e atuação do Poder Judiciário", cadastrada na UVV, com o apoio da Funadesp, além de algumas produções internas, alcançou-se também a elaboração do presente artigo científico. Neste artigo, buscaram-se reflexões acerca da problemática envolvendo o Direito Ambiental, a atuação do Poder Judiciário e a expansão econômica pelo petróleo, por meio da hipótese centrada na análise de uma possível interferência desse Poder na atuação da Administração Pública.

Assim, com base nessa problematização, lograram-se alguns apontamentos conclusivos, conforme se vê a seguir.

1) A proposta trazida pela Constituição de 1988, no âmago de um projeto de construção de um Estado Democrático de Direito, introduz no âmbito normativo uma galopante preocupação com a questão ambiental, acompanhando, inclusive, uma tendência mundial manifestada, sobretudo, em tratados internacionais. Todavia, ocorre que a "globalização da proteção ambiental" convive ora paralelamente, ora contraditoriamente, com a globalização do "desenvolvimento" econômico. Diante delas o Direito, 
em seu paradigma moderno, se vê em diversos momentos em encruzilhadas labirínticas.

Essas encruzilhadas surgem no âmbito da decidibilidade jurídica, momento em que se tem o ápice da aplicattio, no sentido gadameriano (GADAMER, 1996) de compreensão-interpretação-aplicação, hermenêutica. Ou seja, a questão que se coloca envolve desde a maneira como aplicar a lei e, consequentemente, construir a norma jurídica (se a discussão será meramente dogmática e aí se tem uma redução à esfera puramente legalista, vide decisão comentada dogmaticamente aqui), até a própria postura assumida pelo Poder Judiciário, com base nas possibilidades abertas pela CF/1988 no Brasil. Sobre esse segundo ponto, este texto abordou o fenômeno da judicialização da política e do ativismo judicial.

2) No caso em tela, antes mesmo de se abordar a intervenção ou não do Judiciário em políticas públicas (expansão econômica pela exploração do petróleo, proteção ambiental, etc.), foi preciso se estabelecer uma breve distinção entre a judicialização e o ativismo. Considerando-se o segundo como uma possível consequência do primeiro, Canotilho apresenta certa rejeição ao ativismo, quando afirma que "além de se limitarem a sentenças casuísticas [...], falta-lhes legitimidade para a apreciação político-judicial das desconformidades constitucionais das políticas públicas" (CANOTILHO, 2009, p. 57).

Embora se possa pensar o contrário, segundo Streck (2009, p. 73), não cabe aos juízes uma liberdade de escolhas nas suas decisões judiciais, em que pesem as decisões relativas ao exercício do ativismo judicial. O trabalho do intérprete é compreender o fenômeno e encontrar a resposta mais adequada à Constituição. A resposta esperada é a que melhor se adéque aos princípios e regras constitucionais para a solução do caso concreto. Com isso, é possível controlar a atividade jurisdicional, do 
mesmo modo que é possível controlar a discricionariedade administrativa do administrador público.

Desse modo, além de se criticar dogmaticamente, como fora feito no último item deste texto, também se pode questionar se é legítimo ao julgador afastar a obrigatoriedade de compensação imposta por um órgão de fiscalização administrativo que, em tese, teria empreendido a devida análise técnica sobre aquele caso específico. Ao afastar aquela exigência do órgão de proteção ambiental, não estaria o Judiciário se arvorando na condição de gestor? Não seria isso uma exceção no exercício da possibilidade de um Poder interferir no outro?

Quais seriam os limites dessa interferência? Esse pode ser um pano de fundo que vem sendo requestionado diante de enfrentamentos tão polêmicos e atuais como o da exploração do petróleo em face da proteção do meio ambiente.

3) Como dito alhures, o debate em torno dos limites da expansão da atividade econômica impostos pela necessidade de proteção do equilíbrio ecológico ainda não encontra eco suficiente no Poder Judiciário capixaba, no que tange ao julgamento de causas envolvendo a exploração de petróleo no litoral do Espírito Santo. Assim, uma das conclusões que se pode alcançar é justamente o caráter ainda incipiente da apreciação desse tipo de demanda pelo Poder Judiciário, seja na esfera federal seja na estadual em terras capixabas, não obstante o assustador avanço desse tipo de atividade econômica no Estado que, como noticiado anteriormente, ocupa o segundo lugar no ranking nacional de exploração de petróleo.

4) No que se refere à natureza jurídica da licença ambiental, trata-se, na verdade, de uma autorização administrativa concedida pelo Poder Público para o particular exercer uma determinada atividade econômica que seja potencialmente danosa ao meio ambiente. Em se tratando de um bem difuso, que vai 
além do conceito de bem público, por transcender aos interesses da Administração Pública, há que se ter maior cautela no trato desse bem tão valioso.

Por isso, se por um lado não parece prudente deixar o meio ambiente à mercê dos totais interesses do particular; por outro, a atuação de sua fiscalização e "controle" também não pode estar totalmente "protegida" pelo "arbítrio" do julgador. Em outras palavras, o meio ambiente não deve ser colocado à disposição da esfera subjetiva dos interesses de ninguém, seja um particular, seja o Estado-juiz. Diante disso, pelas razões expostas, a licença ambiental deve ser tratada como uma autorização para exploração de atividade econômica potencialmente danosa ao meio ambiente, devendo ser concedida com muita cautela e com base em estudos científicos para se evitar danos muitas vezes irreversíveis.

\section{Referências}

BAUMAN, Z. Modernidade líquida. Rio de Janeiro: J. Zahar, 2001.

BECK, U. La sociedad del riesgo. Barcelona: Paidos, 1998.

BELTRÃO, A. F. G. Curso de direito ambiental. São Paulo: Método, 2009.

BONIFÁCIO, A. C. Normatividade e concretização: a legalidade constitucional. In: MOURA, L. S. M. de (Org.). O novo constitucionalismo na era pós-positivista: homenagem a Paulo Bonavides. São Paulo: Saraiva, 2009. p. 209-226.

BRASIL. Lei n. 6.938, de 31 de agosto de 1981. Dispõe sobre a Política Nacional do Meio Ambiente, seus fins e mecanismos de formulação e aplicação, e dá outras providências. Diário Oficial [da] República Federativa do Brasil, Poder Legislativo, Brasília, DF, 31 ago. 1981. Disponível em: <http://www.planalto.gov. br/ccivil_03/leis/L6938.htm>. Acesso em: 23 dez. 2011. 
BRASIL. Constituição (1988). Constituição: República Federativa do Brasil. Brasília, DF: Senado Federal, 1988.

BRASIL. Lei n. 9.478, de 6 de agosto de 1997. Dispõe sobre a política energética nacional, as atividades relativas ao monopólio do petróleo, institui o Conselho Nacional de Política Energética e a Agência Nacional do Petróleo e dá outras providências. Diário Oficial [da] República Federativa do Brasil, Poder Legislativo, Brasília, DF, 6 ago. 1997. Disponível em: <http://www.planalto.gov. br/ccivil_03/leis/L9478.htm>. Acesso em: 23 dez. 2011.

BRASIL. Lei n. 9.985, de 18 de julho de 2000. Regulamenta o art. 225, § 1o, incisos I, II, III e VII da Constituição Federal, institui o Sistema Nacional de Unidades de Conservação da Natureza e dá outras providências. Diário Oficial [da] República Federativa do Brasil, Poder Legislativo, Brasília, DF, 18 jul. 2000. Disponível em: 〈http://www.planalto.gov.br/ccivil_03/leis/L9985.htm〉. Acesso em: 23 dez. 2011.

BRASIL. Conselho Nacional do Meio Ambiente. Resolução Conama n. 237, de 19 de dezembro de 1997. Dispõe sobre a revisão e complementação dos procedimentos e critérios utilizados para o licenciamento ambiental. Disponível em: $<$ http://www. mma.gov.br/port/conama/legiabre.cfm?codlegi=237 > . Acesso em: 23 dez. 2011.

CANOTILHO, J. J. G. O ativismo judiciário: entre o nacionalismo, a globalização e a pobreza. In: MOURA, L. S. M. de. (Org.). O novo constitucionalismo na era pós-positivista: homenagem a Paulo Bonavides. São Paulo: Saraiva, 2009. p. 47-58.

CARVALHO, D. Petróleo em alta no ES. Royalties dão impulso à economia local. Jornal do Brasil, n. 8369, 7, 2004. Disponível em: <http://infoener.iee.usp.br/ infoener/hemeroteca/imagens/83697.htm>. Acesso em: 27 dez. 2011.

CARVALHO FILHO, J. dos S. Manual de direito administrativo. 23. ed. Rio de Janeiro: Lumen Juris, 2010.

DI GIORGIO, R. Direito, democracia e risco: vínculos com o futuro. Porto Alegre: SAFE, 1998. 
DWORKIN, R. 0 império do direito. Tradução de Jéferson L. Camargo. São Paulo: M. Fontes, 2003.

FONTENELLE, M; AMENDOLA, C. M. Licenciamento ambiental do petróleo e gás natural. Rio de Janeiro: Lumen Juris, 2003

GADAMER, H.-G. Verdad y método: fundamentos de una hermenéutica filosófica. 6. ed. Salamanca: Sígueme, 1996.

GARAPON, A. O juiz e a democracia: o guardião de promessas. Tradução de Maria L. de Carvalho. Rio de Janeiro: Renovar, 1999.

GOVERNO DO ESTADO DO ESPÍRITO SANTO. Petróleo e gás natural. 2009. Disponível em: <http://www.es.gov.br/EspiritoSanto/paginas/petroleo_gas.aspx>. Acesso em: 30 out. 2011.

GUIDDENS, A. As conseqüências da modernidade. São Paulo: UNESP, 1991.

HABERMAS, J. Direito e democracia: entre facticidade e validade. 2. ed. Rio de Janeiro: Tempo Brasileiro, 2003.

MACHADO, P. A. L. Direito ambiental brasileiro. 17. ed. São Paulo: Malheiros, 2009. MILARÉ, É. Direito do ambiente: a gestão ambiental em foco. 6. ed. São Paulo: RT, 2009.

NEVES, R. S. O Estado Regulador: a dignidade humana como princípio informador da regulação do mercado. Revista de Direito Constitucional e Internacional, São Paulo, v. 44, p. 209-233, 2003.

OST, F. A natureza à margem da lei: a ecologia à prova do Direito. Tradução de Joana Chaves. Lisboa: Piaget, 1995.

PEREIRA, A. Licenciamento ambiental: entrave ao desenvolvimento ou necessidade de preservação? In: BRAGA FILHO, E. de O. et al. (Coord.). Advocacia ambiental: segurança jurídica para empreender. Rio de Janeiro: Lumen Juris, 2009. p. 255-266. 
RECURSO ESPECIAL n. 1.079.713 - SC (2008/0169678-0). Disponível em: <http://www.jusbrasil.com.br/jurisprudencia/6061190/recurso-especial-resp1079713-sc-2008-0169678-0-stj/inteiro-teor >. Acesso em: 27 dez. 2011.

RODRIGUES, M. O. A. A prestação jurisdicional na efetivação dos direitos fundamentais. In: MOURA, L. S. M. de. (Org.). 0 novo constitucionalismo na era pós-positivista: homenagem a Paulo Bonavides. São Paulo: Saraiva, 2009. p. 371-396.

SALLES, M. Prefeitura e Petrobras anunciam início das obras de sede administativa. 2007. Disponível em: <http://legado.vitoria.es.gov.br/diario/2007/0426/prefeito_petrobras.asp >. Acesso em: 27 dez. 2011.

SARLET, I. W.; FENSTERSEIFER, T. O papel do Poder Judiciário brasileiro na tutela e efetivação dos direitos e deveres socioambientais. Revista de Direito Ambiental, São Paulo, n. 52, p. 73-100, out./dez. 2008.

SILVA, J. A. da. Direito ambiental constitucional. 7. ed. São Paulo: Malheiros, 2009.

STRECK, L. L. A hermenêutica jurídica nos vinte anos da Constituição do Brasil. In: MOURA, L. S. M. de (Org.). O novo constitucionalismo na era pós-positivista: homenagem a Paulo Bonavides. São Paulo: Saraiva, 2009. p. 59-83.

VIANNA, L. W.; BURGOS, M. B.; SALLES, P. M. Dezessete anos de judicialização da política. Tempo social, v. 19, n. 2, p. 39-85, 2007.

Recebido: 14/09/2011

Received: 09/14/2011

Aprovado: 12/07/2012

Approved: 07/12/2012 